\title{
A Study on the Prevalence of Premenstrual Dysphoric Disorder in Medical Students
}

\author{
Charan Teja Koganti ${ }^{\oplus 1}$, Neeta Sagar Bobba ${ }^{2}$ \\ ${ }^{1}$ Assistant Professor, Department of Psychiatry, Dr. VRK Womens Medical College, Hospital and Research Center, Hyderabad, Telangana, India, ${ }^{2}$ Sri Ramachandra \\ Medical College \& Research Institute, MBBS Student, Chennai, Tamilnadu, India.
}

\section{Abstract}

Background: Premenstrual dysphoric disorder is a common yet underdiagnosed mental health problem among women of reproductive age group with a significant potential to perturb the social, occupational, academic and interpersonal milieu of the suffering women. The aim of the study is to determine the frequency and severity of the premenstrual dysphoric disorder (PMDD) in medical college students. The premenstrual dysphoric disorder is a common yet underdiagnosed mental health problem among women of reproductive age group with a significant potential to perturb the social, occupational, academic and interpersonal milieu of the suffering women. Subjects and Methods: Premenstrual dysphoric disorder was diagnosed based on Penn's daily symptom rating scale (self-administered for 2 months) and an interview-based on diagnostic and statistical manual -5 diagnostic criteria for the premenstrual dysphoric disorder. Results: Overall 180 subjects were studied. The prevalence of premenstrual dysphoric disorder was wound to be $11.11 \%(n=20)$. The most common symptoms found were fatigue irritability, mood swings and A significant correlation between the severity of premenstrual and menstrual difficulties was found with PMDD. Conclusion: The current study highlights the need for clinicians to assess for premenstrual dysphoric disorder in females visiting the hospital with premenstrual and menstrual complaints.

Keywords: Premenstrual Dysphoric Disorder, Menstrual Complaints

Corresponding Author: Charan Teja Koganti, Assistant Professor, Department of Psychiatry, Dr. VRK Womens Medical College, Hospital and Research Center, Hyderabad, Telangana, India.

E-mail: Drcharantejakoganti@gmail.com

Received: 3 May 2020

Revised: 30 May 2020

Accepted: 15 June 2020

Published: 25 June 2020

\section{Introduction}

The premenstrual syndrome (PMS) is a common clinical condition affecting many women during reproductive years. According to estimates by epidemiological surveys, as many as $80 \%$ of women experience some vexing symptoms related to the premenstrual period. ${ }^{[1]}$ The worldwide prevalence of premenstrual dysphoric disorder (PMDD) is estimated to be $3 \%$ to $9 \% .{ }^{[2]}$ According to western literature, there is an enormous amount of health care and the economic burden associated with PMS and PMDD. In India, more than onefourth $(27.7 \%)$ of the female population falls in the 15 to 25 year age-group. Worldwide literature shows that women are more likely to develop depression and anxiety disorders. ${ }^{[3,4]}$ Still, there is a lack of gender-specific studies in terms of mental disorders. Also, most of the studies about women's mental health in India focus on postpartum depression or older age-group. Premenstrual syndrome and PMDD comprise the understudied areas in the Indian context. The reproductive period with menstruation has increased in the life of an average Indian woman, owing to the early onset of menarche, contraceptive methods, and better nutrition. It is crucial to study the levels of impairment and distress due to premenstrual symptoms. The objectives of this study were to identify the prevalence, categorize and rank the symptoms, and grade the levels of severity and impairment in PMS/ PMDD among Indian college students.

PMS is considered as a less severe form of PMDD. Both conditions are associated with physical, emotional, and behavioral symptoms. The physical symptoms of PMS include lower backaches, breast tenderness (mastalgia), swelling, bloating, headaches, etc. Irritability and mood swings and are some of the most commonly reported symptoms of PMS. There can also be anxiety, tension, sadness, feeling of being overwhelmed, or being out of control. The mood symptoms can be very debilitating and may lead to marked impairment in the occupational, social, and interpersonal domains of a woman's life. Sleep disturbance, which can either be insomnia 
or hypersomnia, is among the commonly reported behavioral symptoms.

This condition can be managed by lifestyle modification, exercise, and medication in more severe cases. Hence, this study was planned to explore this obscure area of prime importance.

\section{Subjects and Methods}

Study design: An observational study

Plan \& Duration of the study: The study was conducted at Dr. VRK Womens Medical Science \& Research Centre Hyderabad from Sep-Dec 2019.

Sample size: 200

Methodology: Unmarried Medical Students aged 18-25 yrs with regular menstrual periods for the last 6 months were recommended by conventional sampling. PMDD related data was collected on Penn's daily symptoms rating scale two prospective cycles.

Health-related quality of life data was collected on a medical outcome study

Short-form 36 (SF-36) after taking informed consent from participants

\section{Statistical analysis}

The descriptive and informative analysis was done by a twotailed t-test and multivariate logistic regression analysis.

\section{Results}

Total of 200 subjects were approached, of which 180 were included in the study

\section{Prevalence of PMMD}

In our study, $11.11 \%$ of the subjects were diagnosed as having PMDD. In the present study Prevalence was 14\%

Table 1: Distribution of subjects according to the presence of PMDD.

\begin{tabular}{ll|l}
\hline PMDD & $\begin{array}{l}\text { Number of sub- } \\
\text { jects }\end{array}$ & Percentage (\%) \\
\hline Absent & 160 & $88.88 \%$ \\
\hline Present & 20 & $11.11 \%$ \\
\hline Total & 180 & 100.0 \\
\hline
\end{tabular}

\section{Sociodemographic Correlates of PMDD Age}

In our study, the majority of the subjects were 18-21 years of age $(66.11 \%)$ followed by, $22-25$ years of age $(33.88 \%)$. The mean age was 21.21 years. PMDD was predominantly seen in $18-19$ years of age as compared to other age groups.

\section{Socio-economic Status}

In the present study, the majority of the subjects were from the upper middle and middle class (61\%). Only $26.66 \%$ and $8.88 \%$ of subjects were from upper and lower-middle classes respectively. PMDD was seen in $9 \%$ of subjects, $42 \mathrm{C} \%$ of these were from the upper class, $28 \%$ from upper-middle-class, $23 \%$ from middle class and $6 \%$ were from lower middle class. The differences were not statistically significant, indicating that the symptoms were uniform across all socioeconomic statuses.

\section{Marital Status}

$93.3 \%$ of the subjects in our study were unmarried, while $6.6 \%$ were married. Of those who had PMDD, $94 \%$ were unmarried and $6 \%$ were married.

\section{Regularity and Interval of Menstrual Cycle}

In our study, the majority of the females $(71.66 \%)$ had a regular menstrual cycle. The majority of females who had PMDD reported having irregular menstrual cycles. The differences were statistically significant. $66.66 \%$ females had cycle of $26-$ 30 days; followed by $31-35$ days $(24.4 \%), 21-25$ days $(7.2 \%)$, $36-40$ days $(1.1 \%)$ and $41-45$ days $(0.55 \%)$. The mean duration of the cycle was 27.88 days.

\section{Age of Menarche}

In our study majority of females attained their menarche at age group 12-14 years (65.5\%) followed by 15-17 year age (26.7\%) and age 9-11 year (7.8\%).

Among those who had PMDD, 70.6\% attained their menarche at $12-14$ years of age followed by $15-17$ years of age (27.2\%) followed by $9-11$ years of age (7.22\%). The differences were not statistically significant indicating that PMDD symptoms do not vary with the age of onset of menarche.

\section{Family History of Depression}

In our study, $21.1 \%$ of females reported a positive family history of depression while $78.8 \%$ reported a negative family history of depression. PMDD was seen in $7 \%$

\section{Phenomenology}

Among the studied symptoms, fatigue (38\%), mood swing (43\%)and irritability $(30 \%)$ were the most commonly reported symptoms followed by feeling hopeless(48.7\%); headache(45.05); anxiety (32\%); swelling/bloating sensation $(20 \%)$; depression(12\%); body aches(39.8\%)craving for food (40); low interest in usual activities (32.5\%); breast tenderness $(29.3 \%)$; feeling overwhelmed and out of control (29.3\%); abdominal cramps (20\%); difficulty in concentration $24.6 \%$ ); sleep disturbance (18\%). Very few females had very severe symptoms 


\begin{tabular}{|c|c|c|c|c|c|}
\hline \multirow{3}{*}{$\begin{array}{l}\text { Demographic details } \\
\text { Age(years) 18-21 22-25 } \\
\text { Socio-economic status Upper } \\
\text { Upper-middle Middle Lower- } \\
\text { middle Lower }\end{array}$} & \multirow{3}{*}{ 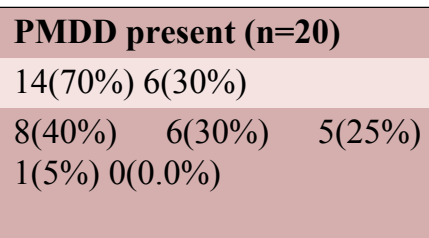 } & \multicolumn{2}{|c|}{ PMDD absent $(n=160)$} & \multicolumn{2}{|c|}{ Total Number $(\mathrm{n}=180))$} \\
\hline & & \multicolumn{2}{|c|}{$105(65.6 \%) 55(34.3 \%)$} & \multicolumn{2}{|c|}{$119(66.11 \%) 61(33.88 \%)$} \\
\hline & & $\begin{array}{l}40(25 \%) \\
50(31.25 \%) \\
0(0.0 \%)\end{array}$ & $\begin{array}{r}45(28.12 \%) \\
15(9.37 \%)\end{array}$ & $\begin{array}{l}48(26.66 \%) \\
55(30.55 \%) \\
0(0.0 \%)\end{array}$ & $\begin{array}{r}51(28.33 \%) \\
16(8.88 \%)\end{array}$ \\
\hline $\begin{array}{l}\text { Marital status Married } \\
\text { Unmarried }\end{array}$ & $2(10 \%) 18(90 \%)$ & $10(6.25 \%) 15$ & $0(93.75 \%)$ & $12(6.66 \%) 1$ & $3.33 \%)$ \\
\hline $\begin{array}{l}\text { Menstrual cycle Regular } \\
\text { irregular }\end{array}$ & $9(45 \%) 11(55 \%)$ & $120(75 \%) 40$ & $28.15 \%)$ & $129(71.66 \%$ & $(28.33 \%)$ \\
\hline \begin{tabular}{lrr} 
Intervalof & \multicolumn{2}{r}{ menstrual } \\
cycle(days) & $21-25$ & $26-30$ \\
$31-35$ & $36-40$ & $41-45$
\end{tabular} & $\begin{array}{l}3(15 \%) \quad 10(50 \%) \\
1(5 \%) 0(0.0 \%)\end{array}$ & $\begin{array}{l}10(6.25 \%) \\
38(23.75 \%) \\
1(0.62 \%)\end{array}$ & $\begin{array}{r}110(68.25 \%) \\
1(0.62 \%)\end{array}$ & $\begin{array}{l}13(7.2 \%) \\
44(24.44 \%) \\
1(0.55 \%)\end{array}$ & $\begin{array}{r}120(66.66 \%) \\
2(1.11 \%)\end{array}$ \\
\hline $\begin{array}{l}\text { Age of menarche(year) 9-11 } \\
12-14 \quad 15-17\end{array}$ & $3(15 \%) 14(70 \%) 3(15 \%)$ & $\begin{array}{l}10(6.25 \%) \\
46(28.75 \%)\end{array}$ & $104(65 \%)$ & $\begin{array}{l}13(7.22 \%) \\
49(27.2 \%)\end{array}$ & $118(65.55 \%)$ \\
\hline $\begin{array}{l}\text { Family history of depression } \\
\text { Present absent }\end{array}$ & $8(40 \%) 12(60 \%)$ & $30(18.75 \%)$ & $30(81.25 \%)$ & $38(21.1 \%)$ & $78.8 \%)$ \\
\hline
\end{tabular}

\begin{tabular}{|ll}
\hline Table 3: Effective and Somatic symptoms & \\
\hline Symptoms & Percentage (\%) \\
\hline Somatic symptoms & $40 \%$ \\
\hline Headache & \\
\hline Effective symptoms & $43 \%$ \\
\hline Moods wings & $40 \%$ \\
\hline Ache & $38 \%$ \\
\hline Fatigue & 20 \\
\hline Breast tenderness & 20 \\
\hline Bloating & 20 \\
\hline Swelling & 30 \\
\hline Irritability & 12 \\
\hline Depression & 32 \\
\hline Anxiety & 19 \\
\hline Increased appetite & 20 \\
\hline Cramps & 18 \\
\hline Insomia or Hypertension & \\
\hline
\end{tabular}

\section{Discussion}

Each menstrual cycle represents a duration in life of a female where nature prepares her body to support pregnancy. The complex interplay between various hormones like LSH, estrogen and progesterone does not only results in various physical changes in the body of a woman but by interaction with other factors it also results in polymorphic behavioural and psychological symptoms. ${ }^{[1]}$ Due to the myths and taboos associated with the menstrual cycle women, especially in rural area, are often reluctant to discuss the physical and psychological problems that are recurrently associated with their periods.

Based on the empirical data, a task force of experts on PMDD submitted a report to APA DSM-5 executive committee in 2012 and recommended the promotion of PMDD from the appendix of DSM -IV to the main body of DSM-5 under the category of depressive disorder. Currently, PMDD is listed as a separate diagnostic in DSM-5 under a diagnostic code 625.4. ${ }^{[2]}$ 


\begin{tabular}{|c|c|c|c|c|c|c|}
\hline SN & Symptoms & Not at all & Mild & Moderate & Severe & Very Severe \\
\hline 1 & Fatigue & 45 & 90 & 40 & 5 & 0 \\
\hline 2 & Co-ordination & 165 & 13 & 2 & 0 & 0 \\
\hline 3 & $\begin{array}{l}\text { Overwhelmed/out } \\
\text { of control }\end{array}$ & 130 & 30 & 19 & 1 & 0 \\
\hline 4 & $\begin{array}{l}\text { Feeling of } \\
\text { hopeless- } \\
\text { ness/Worthlessnes }\end{array}$ & 90 & 40 & 48 & 2 & 0 \\
\hline 5 & Headache & 100 & 60 & 20 & 0 & 0 \\
\hline 6 & Anxiety & 110 & 40 & 30 & 0 & 0 \\
\hline 7 & $\begin{array}{l}\text { Aches / Body } \\
\text { Aches }\end{array}$ & 110 & 40 & 28 & 4 & 0 \\
\hline 8 & Irritability & 85 & 45 & 40 & 10 & 0 \\
\hline 9 & Mood swings & 80 & 60 & 35 & 5 & 0 \\
\hline 10 & Swelling/Bloating & 110 & 38 & 30 & 10 & 2 \\
\hline
\end{tabular}

Irritability has been identified as the most common premenstrual symptom in the United States and European samples. ${ }^{[3,4]}$ However, a recent analysis of community and clinical samples for DSM-5 demonstrated that mood swings or affective liability was the most severe premenstrual affective symptom, followed by irritability. ${ }^{[5]}$ In Casablanca, McHichialamiKh et al (2002), conducted a study to evaluate the prevalence of a potential premenstrual dysphoric disorder (PMDD) during one menstrual cycle, according to the DSM IV criteria and reported 50.2\% prevalence of potential PMDD. ${ }^{[6]}$ The most severe symptoms reported were fatigue and irritability.

\section{Conclusion}

The premenstrual dysphoric disorder is fairly prevalent in young females of the reproductive age group in general population. Since research participants who were diagnosed with PMDD also have higher intensities of physical symptoms we conclude that patients visiting the gynecological department with moderate to severe premenstrual or menstrual complaints should be screened for PMDD and referred to mental health professionals.

\section{References}

1. Yonkers KA, O'Brien PMS, Eriksson E. Premenstrual syndrome. Lancet. 2008;371(9619):1200-1210. Available from: https://dx.doi.org/10.1016/S0140-6736(08)60527-9.

2. Raval CM, Panchal BN, Tiwari DS, Vala AU, Bhatt RB. Prevalence of premenstrual syndrome and premenstrual dysphoric dis- order among college students of Bhavnagar, Gujarat. Indian J Psychiatry. 2016;58(2):164-170. Available from: https://dx.doi. org/10.4103/0019-5545.183796.

3. Hartlage SA, Freels S, Gotman N. Criteria for premenstrual dysphoric disorder: secondary analyses of relevant data sets. Arch Gen Psychiatry. 2012;69(3):300-305. Available from: https://dx.doi.org/10.1001/archgenpsychiatry.2011.1368.

4. Pearlstein T, Yonkers KA, Fayyad R, Gillespie JA. Pretreatment pattern of symptom expression in premenstrual dysphoric disorder. J Affect Disord. 2005;85(3):275-282. Available from: https://dx.doi.org/10.1016/j.jad.2004.10.004.

5. Premenstrual Dysphoric Disorder: Epidemiology and Treatment. Curr Psychiatry Rep. 2015;17(11):87. Available from: https: //dx.doi.org/10.1007/s11920-015-0628-3.

6. Alami KM, Tahiri SM, Moussaoui D, Kadri N. Assessment of premenstrual dysphoric disorder symptoms: population of women in Casablanca. Encephale. 2002;28(1):525-530.

Copyright: (C) the author(s), 2020. It is an open-access article distributed under the terms of the Creative Commons Attribution License (CC BY 4.0), which permits authors to retain ownership of the copyright for their content, and allow anyone to download, reuse, reprint, modify, distribute and/or copy the content as long as the original authors and source are cited.

How to cite this article: Koganti CT, Bobba NS. A Study on the Prevalence of Premenstrual Dysphoric Disorder in Medical Students. Acad. J Med. 2020;3(1):74-77.

DOI: dx.doi.org/10.47008/ajm.2020.3.1.15

Source of Support: Nil, Conflict of Interest: None declared. 